\title{
Impact of Exploitative Leadership on Workplace Incivility: Role of Psychological Distress -Evidence from Banking Sector
}

\author{
Aamir Saif Kiyani' ${ }^{1}$, Mesut Atasever², Syed Tahir Hussain Rizvi ${ }^{3}$ \\ ${ }^{1} \mathrm{PhD}$ Scholar, FMS, International Islamic University Islamabad, Pakistan. \\ ${ }^{2}$ Assistant Professor, Faculty of Applied Sciences, Usak University Turkey \\ ${ }^{3}$ Assistant Professor, FMS, International Islamic University Islamabad, Pakistan
}

\section{A B S T R A C T}

Aim: The present study investigated the effect of exploitative leadership on workplace incivility banking Sector employee with the role of psychological stress as a moderator

Background: Destructive leadership, mostly exploitative leadership, had been less thoughtful earlier in banking research. Additionally, fundamental mechanisms and boundary conditions that occur between exploitative leadership and employee outcomes such as workplace incivility were also missing in the banking literature with the context of psychological distress.

Methods: This present research quantitative nature in which data had collected from the banking Sector $(N=310)$ working in the Pakistani banking sector through self-administrative questionnaires.

Results: psychological distress moderate the relationship between exploitative leadership and workplace incivility among banking sector employees when psychological distress was high.

Conclusions: Exploitative leadership had a significant impact on outcomes in the form of workplace incivility and psychological distress significantly moderating between exploitative leadership and workplace incivility when psychological distress was high in the banking sector in Pakistan

Implications for Banking Sector Management: It is among the pioneer studies to unveil the exploitative side of leadership and its negative consequences for banking sector employees. Psychological distress in the banking sector can be reduced by discouraging leader exploitative behavior. Banking can utilize workplace incivility from work as a tool to reduce destructive outcomes of leader exploitative behavior.

Key words: Exploitative leadership, Workplace incivility, leadership, psychological distress, leadership, Banking Sector Pakistan

\section{INTRODUCTION}

Leadership plays an important role at the workplace and significantly influences the followers' bahvior. The direction, allocate responsibilities to achieve organizational goals (Mehwish \& Tasneem, 2020). In literature three different types of destructive leadership, their consequences, and their effect on followers have been studied. These 
studies focused more on exploitative supervision, abusive supervision and destructive supervision to differentiate between different types of negative leadership, showing selfinterested behavior of leaders. (Braun, Kark, \&Wisse, 2019).

The exploitative leadership concept was introduced in recent times that is truly self-seeking, like obtaining credit from follower's work and using followers for personal gains (Schmid, Verdorfer, and Peus 2019). The primary objective of exploitative leadership behaviors is to fulfill self-interest of the leader. People are exploited by such leaders in many ways, like exerting pressure on followers, overburdening them and putting those challenging conditions, allowing no development followers (Schmid et al., 2019 , p.4). The exploitative leaders are always informal with their followers and have smiles on their faces for achieving their personal goals as compared to destructive leadership styles. (Schmid et al., 2019). Exploitative leaders have a smile on their faces and exhibit anover-friendly body language, but deep inside, they are busy thinking of ways to achieve their personal goals through their subordinates (Schmid, Verdorfer \& Peus, 2017).

In literature, a study tested the impact of exploitative leadership on the intention and emotions of workers, while the other study exposed two adverse results this type of leadership such as workplace deviance and job burnout (Schmid et al., 2018; Schmid et al., 2019). Apart from its negative results for workers, there is very little research available about this leadership style. These two studies have tested the outcomes of exploitative leadership in a variety of public and private organizations; but still there is literature available on its association with health-related results such as psychological distress. Most of the literature has highlighted the predictors of psychological distress such as job demands and hard-working conditions (Hasan \& Tumah, 2019; Heijden, Brown Mahoney, \& Xu, 2019), while exploitative leadership styles was not considered under the domain of destructive leadership.

A large number of researchers now agree on the notion that destructive leadership is a difficult phenomenon and complicated to analyze (e.g., Schilling, 2009; Thorough good, Tate, Sawyer, \&Jacobs, 2012). Exploitative leadership is very hard to recognize as such leaders are pleasant and friendly from outside and exploitative, as well 
as manipulative from inside. Significant amount of research has already been done on the destructive leadership styles which improved our understanding of this leadership domain (Schyns, Neves, Wisse\& Knoll, 2018; Thoroughgood, Sawyer, Padilla \& Lunsford, 2018). There are still a lot of unexplored avenues in destructive leadership research, particularly in exploitative leadership, that need our immediate attention.

As compared to destructive leadership exploitative leadership behavior is more dangerous that is why there is an instantaneous need to study the effects of exploitative leadership (Schmid et al., 2019). Exploitative leaders are selfish leaders who exploit and influence their supporters secretly by discouraging them, pressurizing them, giving them more workload, and even creating hurdles in their development (Schmid et al., 2019). This shift from positive to the negative side of leadership has given rise to a novel landscape that contains a lot of new concepts, all of which highlight the different ways leaders might show bad behaviors at the same time highlighted the antecedents, as well as, consequences of these behaviors (Shaw, Erickson \& Harvey, 2011; Schyns and Schilling 2013; Sheaffer, 2018; Schimd, Verdorfer \& Peus, 2018). Since this type of leadership is neglected, there is dire need to explore the affects of exploitative leadership (Naseer et al., 2016).

Workplace incivility is an exhibition of uncivil interaction from different sources which can source from coworkers or supervisors (Schilpzand, Pater, \&Erez, 2016). Leaders' use of 'low-intensity deviant behavior with hidden intention to harm the worker, in violation of workplace norms for mutual respect, is very common in organizations. Uncivil behaviors are characteristically rude and discourteous, displaying a lack of regard for others" (Andersson and Pearson, 1999, p. 457). This current study has been conducted to evaluate how exploitative leadership influences instigated workplace incivility through intervening effects of psychological distress, while a leader have the ability to influence others to achieve organizational goals (Erkutlu, \& Chafra, 2018).

Present study has obtained data from organizations within the banking sector of Pakistan which are mostly under dominating leadership, often having traits of exploitative leadership. These organizations suffer from negative outcomes of exploitative leadership like low productivity and workplace incivility among employees. 
Increasing interest in this dysfunctional type of leadership will lead to improve the literature on organizational behavior (Karakitapoðlu Aygun \& Gumusluoglu, 2013). Though various studies have pointed out that this type of leaders negatively affect their subordinates, no study was found that has explained how exploitative leadership instigates workers' impoliteness at work how psychological distress affects this relation.

Psychological distress has been considered on top among workers. There has been a constant call for studying psychological distress in the context of exploitative leader and the workplace incivility (Ghawadra, Abdullah, Choo, \&Phang, 2019; Hasan \&Tumah, 2019). When leaders are indulged in exploitative and manipulative tactics such as overburdening employees, pressurizing them, and under-challenge them, the employees may feel psychological stress, but at the same time, they also start participating in negative workplace gossips about their leader, as a way of releasing their stress and restoring their lost resources (Hobfoll, 1989). According to a research on leadership of view under destructive leadership job distress among the workers is very common (Haider, Nisar, Baig, \&Azeem, 2018; Khan, Imran, \& Anwar, 2019).

\subsection{Research Justification}

This study aims at filling various contextual and theoretical gaps in the literature on exploitative Leadership and workplace incivility identified by previous studies. This study was conducted in the banking sector of Pakistan using conservation of resources theory to explain the relationship between exploitative leadership and workplace incivilities. COR theory as it reflects the potential gain and loss of resources and provides justification of uncivil behavior further moderated by psychological distress.

Organizing the theoretical support of COR theory, we argue that exploitative leadership develops a stressful situation that may cause employees to feel the loss of their potential resources that may result in psychological distress and can become a cause to instigate workplace incivility. The exploitative leadership's arrogant and self-interested behavior put individuals susceptible to heightened psychological strain that could lead them to retaliate and instigates workplace incivility (Loh, \&Loi, 2018). 


\subsection{Conceptual Model}

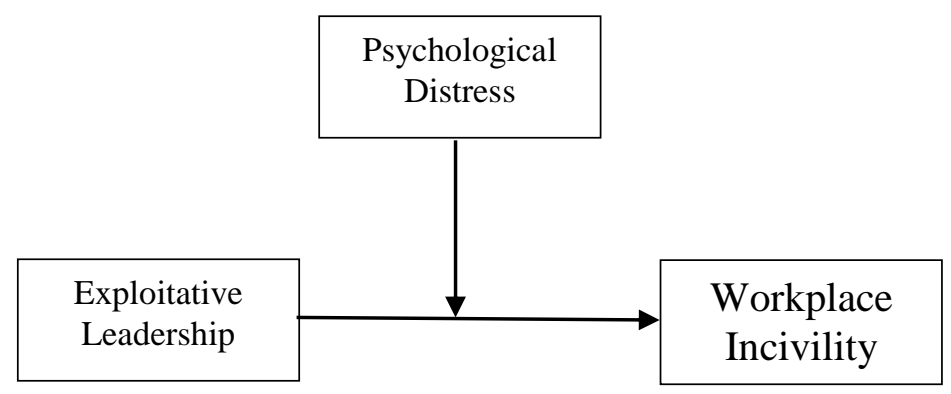

\subsection{Research Questions}

The present research focused on the following research questions:

- What is the effect of exploitive leadership on workplace incivility?

- How psychological distress moderates the relationship between exploitative leadership and workplace incivility.

\subsection{Research Objectives}

- To examine the effect of exploitive leadership on workplace incivility?

- To analyze the moderating effect of psychological distress on the relationship between exploitative leadership and workplace incivility.

\section{LITERATURE REVIEW}

\subsection{Exploitative Leadership and Workplace Incivility}

Exploitative leadership performed by a person who has a special task and ruleoriented perspective and also acts as a key element in the organization among other leaders and followers (Smylie et al., 2005). Researchers studied exploitative leadership and its harmful affects on employee's psychological state, that forces employee to retaliate with incivility at workplace. Such leaders are expected to harm followers' optimism for the future. Hence, an employee who is new in the organization or who scored high in ethical values feels less comfortable in the stressful environment of the organization, and to avoid resource loss instigate workplace incivility. Literature posits out that employees learn negative behavior from others at the workplace (Foulk, Woolum, \&Erez, 2016). Moreover, the followers of destructive leaders also also retaliate 
with workplace incivility as a norm of the workplace because employee perceives a destructive behavior from the leader feel and it over them. If employees are more attentive towards 'self-regulation' and have control over them, they will tolerate and keep themselves away from aggression (Yang, Caughlin, Gazica, Truxillo, \& Spector, 2014). Employees exhibit workplace incivility because they are passing through feelings of condescension, and degradation at work (Burnfield, Clark, Devendorf, \&Jex, 2004). Lazarus and Folkman (1984, p.19) documented that when a worker recognizes psychological stress from the environment, he retaliates with workplace incivilityworkplace incivility. Competing and irrelevant information (Johnson, Chang, \& Lord, 2006).

Workplace incivility has been define as "low-intensity deviant behavior with ambiguous intent to harm the target" (Andersson and Pearson, 1999, p. 457). Hoball,s (1989) reported that Conservation of Resources (COR) theory, people are motivated to preserve, acquires, and maintain the resources. Resources are, "those objects, personal characteristics, conditions, or energies that are valued by the individual or that serve as a means for the attainment of these objects, personal characteristics, conditions, or energies (Hobfoll, 1989, p. 516). Psychologically distressed, burned-out workers instigated workplace incivility toward other persons at the workplace (Blau and Andersson, 2005; van Jaarsveld et al., 2010; Lim \& Cortina, 2005). Because loss of resources is detrimental to their psychological health, followers who do not have any approach towards the leader will become under stress due to interpersonal conflict and negative leadership style. Such an incongruent environment depletes their psychological, social resources. In return, they will instigate incivility at work. So, based on this, we hypothesize:

$\mathbf{H}_{1}$ : Exploitative leadership is positively associated with Instigated workplace incivility.

\subsection{Psychological Distress Moderates the Relationship between Workplace Incivility and Exploitative Leadership}

Psychological distress is conceptualized as a negative mental state characterized by negative beliefs and feelings related to fear, anxiety, and depression (Restubog et al., 2011). According to COR theory, when individuals facing an actual loss of resources or frightened, they will experience psychological strains and try to protect and preserve their 
limited resources Hobfoll, 1989; Hobfoll et al., 2018), particularly workers experiencing psychological distress due to exploitative leadership. COR theory posits that when persons are threatened by depletion of actual resources or loss of potential resources then the damage would occur (Hobfoll, 1989; Hobfoll et al., 2018).

Over time, leaders' exploitative behaviors could cause exploitation of the workers to perceive prolonged negative feelings and a loss (or the threat of a loss) of psychosocial resources (Schmid et al., 2019). Similarly, Livne-Oferetal. (2019) found that employees' perception of an exploitative employee-organization relationship was positively associated with a series of negative emotions including depression and anger that could serve as important indicators of psychological distress. Accordingly, we argue that employees tend to develop a negative mental state, which may manifest as psychological distress when encountering exploitative behaviors from their leaders. Working under an exploitative leader is not easy, you are overburdened, pressurized, manipulated, and taken advantage of. All these things consume the personal resources of employees, as a result of which they experience psychological distress (Schmid, Verdorfer \& Peus, 2018). Conflict between work-family or vice versa may threaten an individual's ability to meet demands in each domain (Peeters et al., 2013), and with the presence of social imbalance together with these factors may predict higher psychological distress.

The impact of supervisor and workplace incivility on psychological distress was also higher among employees of different organizations. Park et al. (2018), found that psychological distress mediated the impact of abusive supervision (reflecting a typical form of resource-depleting leadership) on salience (reflecting a resource protecting mechanism). In this research we demonstrated a moderating role of psychological distress in the relationship between exploitative leadership and workplace incivility.

Drawing on COR theory, we introduced psychological distress as a key moderating role in the relationship between exploitative leadership and workplace incivility and according to COR theory, fundamental motivation of co-worker uncivil behavior may threaten the victim's belongingness that results in resource loss; such loss is expected to have a negative effect on individual health. Based on the theoretical 
arguments, the following hypothesis is proposing that are:

$\mathbf{H}_{2 \mathbf{b}}$ : Psychological distress moderates the relationship between exploitative leadership and workplace incivility when psychological distress is high.

\section{RESEARCH METHODOLOGY}

\subsection{Design}

The present research used the positivist approach and is quantitative time-lagged study Independent variable and moderator were tapped in time one and dependent variable was measured in time two to avoid common method bias (Podsakoff $\&$ orgasm, 1986). Due to the absence of officials in offices data was collected through adopted questionnaires using the convenience non-probability sampling method. Data was collected from public and private banking sector of twin city Rawalpindi \& Islamabad.

Due to coved 19 complete staff were not available so mostly online Questioners were filled-up from respondent at time 1 and Time II. Demographics researches include, workers' age as well their job experience, gender, and their qualification. A total of 450 questionnaires were distributed among the participants, only 310 completely filled questionnaires were received. Response rate was $68.8 \%$. Out of 310 respondents $28 \%$ were graduates (BBA, BS), 51\% had acquired their master's or M Phil degree (MBA, MS $\&$ other), $21 \%$ were having a Ph D degree. The majority were having a Master's degree.

As far as the job tenure is concerned, out of 310 respondents, $27.1 \%$ were having 3 or less than three year experience respondents, $17 \%$ were with an experience of 4-6 years, $34.9 \%$ of respondents had 7-10 years of experience, $11 \%$ respondents had almost 10-12 years of experience, $10 \%$ respondents had an experience of more than 15years.

\subsection{Measures}

Data collection was done in simple English language by using the selfadministered questioners. Data was collected from those participants who met the broad criteria. It was ensured that they do not face any language-related issues and barriers for accurate information (Pasha et al., 2020). Measurement has done on the basis point of five Likert scales to gather the responses with $1=$ strongly disagree to $5=$ strongly agree. 


\subsubsection{Exploitative Leadership}

The Exploitative leader leadership has four dimensions (a) displaying egotistic behavior (b) take work and force admirers, (c) put burden on the admirers (d) focus on to restrain the individual improvement (Schmid, 2019). Data for Exploitative Leadership (EL was collected through a 15-item scale Sample item is, "My leader progresses my competency without seeing my requirements to influence his or her objective." The composite reliability for exploitative leadership for the present study is 0.90 which is shown in below table 1.

\subsubsection{Psychological Distress}

Psychological distress is a negative experience initiated by the stressor in which an individual's feel wide-ranging depressing manifestation, for example, feeling awkward, tired, sleepy, worthless, hopeless \& depressed (Kessler, 2002). Kessler (2002). An adopted 10 item questionnaire was used to measure psychological distress. A sample item states: "Throughout the last thirty days, almost how repeatedly did you feeltired and depress out for the no solid purpose?" The composite reliability for psychological distress in the present study is 0.87 which is shown in table 1 .

\subsubsection{Workplace Incivility}

To measure workplace incivility anadopted 7-item scale of Salanova, Agut \& Pier (2005) was used. Sample item says "Made demeaning, rude or derogatory remarks about someone" The composite reliability for the workplace Incivility (WIC) to this investigation is 0.86 which is shown below in table 3.1. Five Likert scales was used to obtain the response for all variables ranging from 1 coding for disagree to 5 for the Strongly Agree.

\begin{tabular}{|l|l|c|c|}
\hline \multicolumn{4}{|c|}{ Table 3.1: Instrument } \\
\hline \multicolumn{1}{|c|}{ Variables } & \multicolumn{1}{|c|}{ Source } & Items & Cronbach's alpha $(\boldsymbol{\alpha})$ \\
\hline Exploitative Leadership (EL) & Schmid (2019) & 15 & 0.90 \\
\hline Psychological Distress & Kessler et al. (2002) & 10 & 0.87 \\
\hline Workplace Incivility (WIC) & $\begin{array}{l}\text { Salanova, Agut \& } \\
\text { Pier (2005) }\end{array}$ & 7 & 0.86 \\
\hline
\end{tabular}

Table 2 explains the Skewness kurtoses, mean, S.D, bivariate correlation(r), and Composite reliabilities. The present study used a 5-Likert scale from 1 for disagree to 5 
for the strongly agree. So, average values were ranged between $1 \& 5$. Hence, the mean value for exploitative leadership was 4.04, which is greater than the mean value of 2.5 . The high mean value explained that the mostly participant classified their leadership as shown abusive or exploitative behavior. Going additional, the average value for WIC (3.13), and psychological distress (3.11)) was also greater than the mean value. Skewness and kurtosis Value less than \pm 1.96 so the result shown that's over data is normal as suggested by (George \& Mallery 2010).

The bivariate correlation results explained that the exploitative leadership (EL) is positively and significantly correlated to workplace incivility $(r=0.45, p<.001)$ while psychological distress significant, positive interrelated to Exploitative leadership ( $r=$ $0.43, \mathrm{p}<.001)$. Hence, WIC were also significantly and positively correlated with P.D ( $\mathrm{r}$ $=.41, \mathrm{p}<.001)$.

As per the results showing for one-way ANOVA for this studied no demographic variable was significantly related to studied variables. The correlation (r) results were also indicated that there is no statistical relationship between demographic variables and the studied variables. The relationship results for the Research variables as well as demographic variables are providing in Table 2 . The Composite Reliability value of all the variables is more than the maximum limit of 0.70 . (Table 2)

\begin{tabular}{|c|c|c|c|c|c|c|c|c|c|c|c|c|c|c|}
\hline \multicolumn{15}{|c|}{ Table. 3: Multicollinearity } \\
\hline S.\# & Variable & $\mathrm{x}$ & S.D & $\begin{array}{c}\text { Exploitative } \\
\text { leader }\end{array}$ & $\begin{array}{l}\text { Workplac } \\
\text { e incivility }\end{array}$ & $\begin{array}{l}\text { Psychologica } \\
\text { I Distress }\end{array}$ & & Age & Gender & Organization & Designation & Education & City & Experience \\
\hline 1 & E.L & 4.04 & 0.81 & $(0.90)$ & & & & & & & & & & \\
\hline 2 & W.I.C & 3.13 & 0.86 & $0.45^{*}$ & $(0.86)$ & & & & & & & & & \\
\hline 3 & P.D & 3.11 & 0.81 & $0.43^{+*}$ & $0.41^{* *}$ & $(0.87)$ & & & & & & & & \\
\hline 4 & Age & & & - & -0.002 & 0.01 & 0.01 & - & & & & & & \\
\hline 5 & Gender & & & - & -.096 & -0.00 & -0.022 & - & - & & & & & \\
\hline 6 & $\begin{array}{c}\text { Organizatio } \\
n\end{array}$ & & & - & -0.03 & -0.03 & -0.01 & - & - & - & & & & \\
\hline 7 & Designation & & & - & -0.03 & -0.03 & -0.01 & - & - & - & - & & & \\
\hline 8 & Education & & & - & -0.003 & .000 & .030 & - & - & - & - & - & & \\
\hline 9 & City & & & - & 0.03 & 0.11 & 0.33 & - & - & - & - & - & - & \\
\hline 10 & Experience & & & - & 0.001 & 0.00 & 0.08 & - & - & - & - & - & - & - \\
\hline
\end{tabular}




\section{RESULTS AND ANALYSIS}

We have done Variance Inflation Factor through SPSS* Version 22 for exploitative leadership and psychological distress on workplace incivility and performed multivariate regression to investigate multicollinearity. The result revealed that there is no multicollinearity threat in data and every variable clarified and explained unique variance. In our study VIF is 1.88 (VIF < 3) shows that there is no multicollinearity issue within the sample. However, tolerance values 0.91 for all the factors which are higher than 0.10 and close to 1.0 explained good results (O'Brien, 2002).

In the present research, we conduct confirmatory factor analysis (CFA) through Amos to investigate the convergent validity (CV) as well as discriminant validity for each variable. Maximum likelihood (MLH) techniques were used to estimate limitations in Conformity Factor Analysis models. Researchers proposed to use the maximum likely hood (MLH) method for behavioral and social sciences studies, which as adopted as such. Thus, convergent validity was examined by checking the estimated scores for each item, and also through factor loadings. The result indicates that the minimum value for the factor loading is 0.61 , and the maximum value is 0.79 for the present study, so the results show that all of the factors loaded fully on their appreciated variables, therefore, it verifies the convergent validity (CV). Previous research demonstrated that if the value of factor loadings is more or equal to 0.5 that means an acceptable range of convergent validity (Hair, 2010).

The discriminant validity (DV) revealed that each item explained the unique variance and do not overlap with the others. Discriminant validity can be calculated to take the square root of Average Variance Explained (AVE). If the value of Discriminant validity (DV) is greater than 0.70 that means it is an acceptable range (Ziegler, 2011). In the current study, all factors have Discriminant validity greater than 0.70 which revealed that's acceptable range of validity.

CFA was performed through Amos for exploitative leaders, psychological distress, and workplace incivility (Table 3). The results show that CMIN/Diff value of every variable is less than 3 which is in an acceptable range as suggested by the 
Researchers in previous studies (Hu and Bentler, 1999). While result also indicates that's the value of All variables GFI, CFI NFI, AGFI as well TLI are greater than 0.90 which are accepted values as recommended by Hair et al., (2010) present studied these values higher than 0.90 and represent a good model fit. However, the value of RMR 0.027 and RMSEA are 0.069 which are less than .08 that revealed an acceptable model fits as per the recommendation of the prior studies (Tanaka, 1993; Hair., 2010).

\begin{tabular}{|l|c|c|c|c|c|c|c|c|c|c|}
\hline \multicolumn{1}{|c|}{ Table 3. Model fits for all the Variables } \\
\hline Variables & CMIN & DIFF & CMIN/DIFF & CFI & GFI & NFI & AGFI & TLI & RMR & RMSEA \\
\hline $\begin{array}{c}\text { Exploitative } \\
\text { Leadership }\end{array}$ & 466.576 & 310 & 1.506 & 0.95 & 0.91 & 0.90 & 0.91 & 0.91 & 0.017 & 0.039 \\
\hline $\begin{array}{c}\text { Psychological } \\
\text { Distress }\end{array}$ & 450.562 & 220 & 2.045 & 0.91 & 0.971 & 0.971 & 0.94 & 0.97 & 0.03 & 0.033 \\
\hline $\begin{array}{c}\text { Workplace } \\
\text { incivility }\end{array}$ & 102.480 & 76 & 1.342 & 0.90 & 0.91 & 0.98 & 0.97 & 0.97 & 0.040 & 0.050 \\
\hline $\begin{array}{c}\text { Measurement } \\
\text { Model }\end{array}$ & 1435.247 & 928 & 1.5463 & 0.91 & 0.97 & 0.97 & 0.98 & 0.92 & 0.030 & 0.034 \\
\hline $\begin{array}{c}\text { Structural } \\
\text { Model }\end{array}$ & 351.981 & 198 & 1.771 & 0.98 & 0.99 & 0.98 & 0.94 & 0.95 & 0.0315 & 0.042 \\
\hline
\end{tabular}

Preacher and Hayes model 1 were used to test the hypotheses (Hayes et al., 2016). The results revealed that is a direct relationship between Exploitative leadership and workplace incivility in below table 3.4. Hypothesized 1 was exploitive leader (EL) is positive and significant impact on workplace incivility WIC $(\beta=0.271, \mathrm{p}<0.05)$. Hence, H1a was accepted for this study. R square indicates that Exploitative leadership brings $27.10 \%$ change in WIC.

\begin{tabular}{|l|l|l|l|l|l|l|}
\hline \multicolumn{1}{|l|}{ Table 4 } \\
\hline Hypothesis & Variables & $\boldsymbol{\beta}$ & effect & P & LLCI & ULCI \\
\hline H1 & EL WIC & 0.271 & 0.06 & 0.03 & 0.115 & 0.2950 \\
\hline
\end{tabular}

$\mathrm{EL}=$ Exploitative Leader, WIC $=$ Workplace Incivility, $\mathrm{LL}=$ Lower limit, UL $=$ Upper Limit, $\mathrm{CI}=$ Confidence interval, $\mathrm{N}=310$

Process of Hayes (2016) Model 1 bootstrap method were performed also to examine the moderation effect of, Psychological Distress in the relationship between exploitative leadership and workplace incivility. Confidence interval (CI) was calculated $95 \%$ and bootstrap size were 1000 . To investigate the slope of interactive effect basic slope test had been conducted through the SPSS process of Hayes model, 1Standerd 
deviation (SD) high and below the average value which is suggested (Aiken, 1991). While the interaction terms showed (EL X psy distress) was the mean-centered before analysis with the context of workplace incivility (WIC). Result revealed that's table 3.5 Results of Table 5 show that the conditional indirect effect of EL on WIC was Significant $(\beta 0.271, \mathrm{p}<0011)$ While the interaction term result showed also psychological distress $\mathrm{x}$

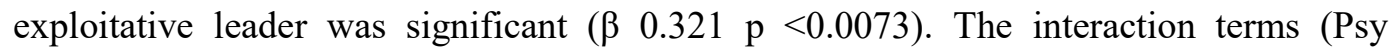
distress X EL) were mean-centered before analysis with the context of WIC. However, adjusted $\Delta \mathrm{R} 2$ due to influences of interaction term is .0211**. The conditional effect shows that in the presence of the psychological distress relationship EL and WIC get stronger and the affect from .0260 to .5465 . The result showed at mean level effect .271 when psychological 1SD low from mean the relationship between EL and WIC were weaker $(\beta 38.18 \mathrm{P}<0.000)$ and when psychological distress 1Standerd deviation (SD) increases above from mean the relationship between EL and WIC were stronger, so hence result shown indicate that when psychological distress decreases 1 SD below from mean the relation between EL and WIC were stronger $(\beta .6482 \mathrm{P}<0.0001), \mathrm{H}_{\mathrm{I}}$ accepted.

\begin{tabular}{|c|c|c|c|c|}
\hline S. No & Predictor & $\beta$ & SE & $\mathbf{P}$ \\
\hline 1 & Constant & $4.10 * *$ & .051 & .0000 \\
\hline 2 & EL & $.271 * *$ & .062 & .0004 \\
\hline 3 & Psychological distress & $.2425^{* *}$ & .072 & .0017 \\
\hline 4 & Interaction term psychological distress x EL & $.321 * *$ & .054 & .0001 \\
\hline
\end{tabular}

\begin{tabular}{|c|c|c|c|c|c|}
\hline \multicolumn{6}{|c|}{ Conditional Effect X on Y } \\
\hline $\begin{array}{c}\text { Psychological } \\
\text { Distress }\end{array}$ & $\mathbf{B}$ & Standard Effect & P & LLCI & ULCI \\
\hline-.9191 & .3818 & .0594 & .0007 & .2334 & .2687 \\
\hline .000 & $.271^{* *}$ & .0362 & .0037 & .1495 & .3706 \\
\hline .9191 & $.6482^{* *}$ & .0582 & .0001 & .3743 & .7485 \\
\hline
\end{tabular}

The result showed that in figure 2 when the psychological distress was low at 1SD from the mean so the relation between EL and WIC was weaker Hence, the relation between EL and WIC was stronger when the psychological distress was high at 1SD above from mean. Interaction term plot figure 2 revealed that when the psychological 
distress increases the relationship between EL and WIC was so strong and when psychological distress low the relationship between EL and WIC was weaker therefore, hypotheses $\mathrm{H}_{2}$ accepted.

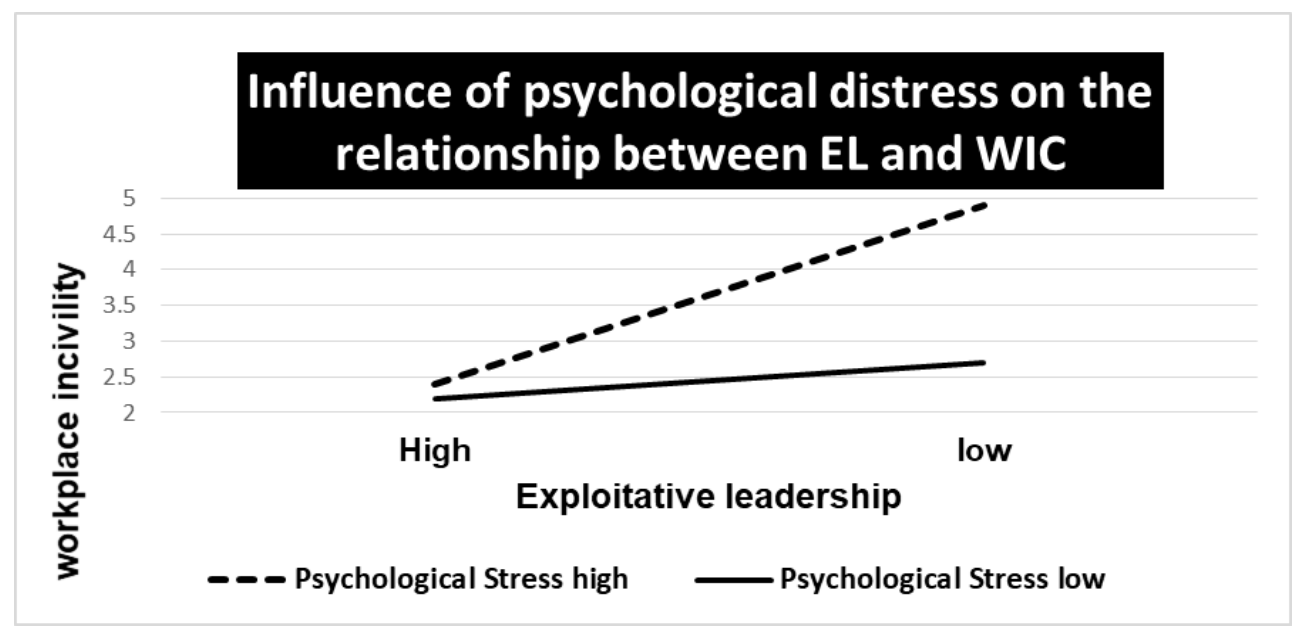

Figure 2 Moderation graph EL=Exploitative Leadership, WIC=Workplace incivility

\section{DISCUSSION}

In the present study data was collected from the employees of banking sector located in twin cities Islamabad and Rawalpindi of Pakistan. After the analysis of the results of the study, it was established that exploitative leadership and employees' workplace incivility is positively related and this relationship gets stronger and Psychological distress was found to be moderating this relationship such that when psychological distress is high this relationship gets stronger while this relationship gets weaker when psychological distress is low.

The findings of the current study will be helpful for managers as well as management to improve challenges and effects of exploitative leadership. Firstly, this research has verified the positive effect of exploitative leadership on work incivility in the Banking sector of Pakistan. Secondly, this research enhances the perspective of the "black box" by fundamental links between manipulative management and their results through indicating the moderating task of psychological distress connecting exploitative leadership and work place of incivility. Therefore, employees may experience 
unfavorable psychological results like (psychological distress) by exposure to manipulative management and subsequently, workers would be forced to implement a policy of reserves defending (Feng and Wang, 2019). Consequently, emotional suffering would enhance the connection between workplace incivility and exploitative leadership.

The results of the study have made a twin contribution. Firstly, this research comes up with an important finding, though on the basis of a very small data, that employees work place incivility is not an independent phenomenon base on mere aggressive personality type or some other reasons like adverse working condition or discrimination, it is a destructive outcome of exploitative supervision/leadership. Second, the incivility at workplace further aggravates when employee undergo psychological distress coming out of the organizational carelessness towards exploitative behaviour of the supervisors.

Schmid et al., (2019) found with the intention of manipulative management leads to condensed restrictions \& upcoming directions and sentimental assurance, and greater burnout, people incivility, labor divergence, and labor family disagreement. Schmid et al. (2018) manifest that manipulative management leads to optimistic effects on revenue plans. On the other hand, the impact of exploitative leadership has been ignored at the workplace incivility. Therefore, by connecting exploitative leadership to a place of work incivility our findings enhance the choice of the present manipulative.

Second, this research enhances our perspective by indicating the moderating role of psychological distress in the relation between exploitative leader and workplace incivility. (Schmid et al., 2018, 2019). According to the theory of COR mental suffering will be introduced as a means of moderating role in the connection between workplace incivility and manipulative management. The findings showed that manipulative management as a distinctive type of assets reducing leadership amplified workers' psychological distress and therefore lead to workplace incivility. These results are consistent with previous research reported by Park et al. (2018), confirming that mental distress enhances the effect of exploitative leadership (highlighting a distinctive type of assets exhausted leadership) on workers (highlighting an assets preserving reaction). In addition, our findings show that COR theory was a very helpful frame to describe the 
impacting process of exploitative/manipulative management, thus highlighting the psychological process by which manipulative management connects to worker incivility.

\section{CONCLUSION}

\subsection{Practical Implications}

This research have some useful implications. Firstly, this research showed that workplace incivility would be enhanced by manipulative management. Therefore, to reduce the happening of exploitative leadership, the banking sector will need to spend more effort and time on it. For example, organizations may assign leadership to such supervisors who has little egoistic dictatorship, and mysterious edge characteristics (e.g., selfishness manipulation and deviance). Moreover, to stop a leader's manipulative performance, leader guidance programs that focus on refining the behaviour of the supervisors must be greatly encouraged.

Secondly, it has been established that mental distress in the presence of manipulative management was also an inducer of workplace incivility. Therefore, managers will be worried about psychological comfort at their place of work for workers. For example, organizations should construct a sympathetic functioning surrounding and help to supply assets-based interventions to support their team strength to deal with the workload. Particularly organizations should think about providing workers with job health maintenance and psychological session aid to help out them discharge pessimistic feelings, refill private valued assets and encourage adapting skills when confronting pessimistic actions. On the other hand, managers are advised to provide with workers guidance and unique training for workers that were high in antagonistic acknowledgment bias than to help them to establish sympathy on others and appreciate that not all misbehaviors are conscious.

\section{Limitations and Future Direction}

Our research has few limitations that will need to be examined in future research. The first drawback is the universalization- the ability of results to a different perspective. The results of the study were obtained on the basis of smaller data from banking center of twin cities if Islamabad and Rawalpindi in Pakistan. The generalizability of outcomes is 
limited therefore, it is encouraged that future research may duplicate this current study in diverse cultural contexts with samples from different sectors.

Secondly is our small sample size, because of time issues, creating barriers and issues for simplifying the findings of this study. So, we advise conducting further studies with larger samples along with other countries and thirdly, from other sectors of Pakistan, other than the banking sector. We believe that there are many other sectors in Pakistan where Exploitative Leadership causes organizational failures or stress for employees. Those sectors need to be explored.

Thirdly due to covid19 lack of availability of employees at offices, we collected data at time 1 and Time II, through online questioners to minimize the common method bias. Upcoming research would collect data using supervisor-subordinate dyads for better results. Further research can consider other moderators like political skill etc. in the context of exploitative management.

However, the present study investigated the role of psychological distress in the relationship between exploitative leadership and work incivility with the context of the COR theories to explain how exploitative leadership affects workplace incivility.

\section{REFERENCES}

Abubakar, A.M., Yazdian F, T. and Behravesh, E. (2018), "A Riposte to Ostracism and Tolerance to Workplace Incivility: A Generational Perspective", Personnel Review, Vol.47, No.2 DOI.10.1108/PR-07-2016-0153 (in press).

Andersson, L. M., \& Pearson, C. M. (1999). Tit for tat? The spiraling effect of incivility in the workplace. Academy of Management Review, 24(3), 452-471.

Bayraktar, S., \& Jim'enez, A. (2020). Self-efficacy as a resource: a moderated mediation model of transformational leadership, the extent of change and reactions to change. Journal of Organizational Change Management, 33(2), 301-317. https://doi.org/10.1108/jocm-12-2018-0368.

Blau, G., \& Andersson, L. (2005). Testing a measure of instigated workplace incivility. Journal of Occupational and Organizational Psychology, 78(4), 595614.

Feng, J. and Wang, C. (2019), "Does abusive supervision always promote employees to hide knowledge? From both reactance and COR perspectives", Journal of Knowledge Management, Vol. 23 No. 7, pp. 1455-1474.

Feng, J. and Wang, C. (2019), "Does abusive supervision always promote employees to hide knowledge? From both reactance and COR perspectives", Journal of Knowledge Management, Vol. 23 No. 7, pp. 1455-1474.

George, D., \& Mallery, P. (2010), "SPSS for Windows step by step. A simple study guideand reference" (10. Baskı).

Ghawadra, S. F., Abdullah, K. L., Choo, W. Y., \& Phang, C. K. (2019). Mindfulness-based 
stress reduction for psychological distress among nurses: A systematic review. Journal of Clinical Nursing, 28(21-22), 3747-3758. https://doi.org/10.1111/jocn.14987.

Guo, L., Cheng, K. and Luo, J. (2020). "The effect of exploitative leadership on knowledge hiding: a conservation of resources perspective", Leadership \& Organization Development Journal, Vol. ahead-of-print No. ahead-ofprint. https://doi.org/10.1108/LODJ-03-2020-0085

Haider, S., Nisar, Q. A., Baig, F., \& Azeem, M. (2018). Dark side of leadership: Employees' job stress \& deviant behaviors in pharmaceutical industry. International Journal of Pharmaceutical Research \& Allied Sciences, 7(2), 125138

Hasan, A. A., \& Tumah, H. (2019). The correlation between occupational stress, coping strategies, and the levels of psychological distress among nurses working in mental health hospital in Jordan. Perspectives in Psychiatric Care, 55(2), 153160. https://doi.org/10.1111/ppc.12292

Hobfoll, S. E. (1989). Conservation of resources: A new attempt at conceptualizing stress. American Psychologist, 44(3), 513-524. https:// doi.org/10.1037/0003066X.44.3.513.

Hobfoll, S. E., Halbesleben, J., Neveu, J. P., \& Westman, M. (2018). Conservation of resources in the organizational context: The reality of resources and their consequences. Annual Review of Organizational Psychology and Organizational Behavior, 5, 103-128. https://doi. org/10.1146/annur ev-orgps ych-03211 7104640

Loh, J. M., \& Loi, N. (2018). Tit for tat: Burnout as a mediator between workplace incivility and instigated workplace incivility. Asia-Pacific Journal of Business Administration.

Karakitapoðlu-Ayg"un, Z., \& Gumusluoglu, L. (2013). The bright and dark sides of leadership: Transformational vs. non-transformational leadership in a nonWestern context. Leadership, 9(1), 107-133.

Khan, N. Z. A., Imran, A., \& Anwar, A. (2019). Destructive leadership and job stress: Causal effect of emotional exhaustion on job satisfaction of employees in call centers. International Journal of Information, Business and Management, 11(1), 135.

Lazarus, R. S., \& Folkman, S. (1984). Coping and adaptation. The Handbook of Behavioral Medicine, 282-325.

Jiang, Z., Hu, X., Wang, Z. and Jiang, X. (2019), "Knowledge hiding as a barrier to thriving: the mediating role of psychological safety and moderating role of organizational cynicism", Journal of Organizational Behavior, Vol. 47 No. 7, pp. 800-818.

Majeed, M., \& Fatima, T. (2020). Impact of exploitative leadership on psychological distress: A study of nurses. Journal of Nursing Management, 28(7), 1713-1724.

Naseer, S., Raja, U., Syed, F., Donia, M. B. and Darr, W. (2016). Perils of being close to a bad leader in a bad environment, exploring the combined effects of despotic leadership, leader-member exchange, and perceived organizational politics on behaviors. The Leadership Quarterly, 27(1): 14-33.

Pircher Verdorfer, A. and Peus, C. (2019), "Shedding light on leaders' self-interest: theory and measurement of exploitative leadership", Journal of Management, Vol. 45 No. 4, pp. 1401-1433 
Restubog, S.L.D., Scott, K.L. and Zagenczyk, T.J. (2011), "When distress hits home: the role of contextual factors and psychological distress in predicting employees' responses to abusive supervision", Journal of Applied Psychology, Vol. 96 No. 4, pp. 713-729.

Sarwar, A., Irshad, M., Zhong, J. Y., Sarwar, S., \& Pasha, R. (2020). Effects of social undermining in families on deviant workplace behaviour in Pakistani nurses. Journal of Nursing Management, 28(4), 938-947. https://doi.org/10.1111/jonm.13027.

Sarwar, A., Naseer, S., \& Zhong, J. Y. (2020). Effects of bullying on job insecurity and deviant behaviors in nurses: Roles of resilience and support. Journal of Nursing Management, 28(2), 267-276. https://doi. org/10.1111/jonm.12917.

Sarwar, A., Irshad, M., Zhong, J. Y., Sarwar, S., \& Pasha, R. (2020). Effects of social undermining in families on deviant workplace behaviours in Pakistani nurses. Journal of Nursing Management, 28(4), 938-947. https://doi.org/10.1111/jonm.13027

Schmid, E. A., Pircher Verdorfer, A., \& Peus, C. (2017). Shedding light on leaders' selfinterest: theory and measurement of Exploitative Leadership. Journal of Management, 0149206317707810.

Schyns, B., Neves, P., Wisse, B., \& Knoll, M. (2018).Turning a Blind Eye to Destructive Leadership: The Forgotten Destructive Leaders. In what's wrong with Leadership? (pp. 189-206). Routledge

Schilpzand, P., De Pater, I. E., \& Erez, A. (2016). Workplace incivility: A review of the literature and agenda for future research. Journal of Organizational Behavior, 37(1). https://doi.org/10.1002/ job.1976

Schmid, E. A., Verdorfer, A. P., \& Peus, C. (2019). Shedding light on leaders' selfinterest: Theory and measurement of exploitative leadership. Journal of Management, 45 (4), 1401-1433.

Schmid, E. A., Pircher Verdorfer, A., \& Peus, C. (2017). Shedding light on leaders' selfinterest: theory and measurement of Exploitative Leadership. Journal of Management, 0149206317707810.

Schyns, B., \& Schilling, J. (2013). How bad are the effects of bad leaders? A metaanalysis of destructive leadership and its outcomes. The Leadership Quarterly, 24(1), 138-158.

Schyns, B., Neves, P., Wisse, B., \& Knoll, M. (2018).Turning a Blind Eye to Destructive Leadership: The Forgotten Destructive Leaders. In what's wrong With Leadership? (pp. 189-206). Routledge

Shaw, J. B., Erickson, A., \& Harvey, M. (2011). A method for measuring destructive leadership and identifying types of destructive leaders in organizations. The Leadership Quarterly, 22(4), 575-590.

Thoroughgood, C. N., Tate, B. W., Sawyer, K. B., \& Jacobs, R. (2012). Bad to the bone: Empirically defining and measuring destructive leader behavior. Journal of Leadership \& Organizational Studies, 19(2), 230-255.

Schmid, E. A., Pircher Verdorfer, A., \& Peus, C. V. (2018). Different shades-different effects? Consequences of different types of destructive leadership. Frontiers in Psychology, 9, 1289. https://doi. org/10.3389/fpsyg.2018.01289.

Van Jaarsveld, D. D., Walker, D. D., \& Skarlicki, D. P. (2010). The role of job demands and emotional exhaustion in the relationship between customer and employee incivility. Journal of Management, 36(6), 1486-1504. 